\title{
Portable and wearable dialysis devices for the treatment of patients with end-stage kidney failure: Wishful thinking or just over the horizon?
}

\author{
Andrew Davenport
}

Received: 14 July 2014 /Revised: 3 September 2014 / Accepted: 16 September 2014 / Published online: 21 October 2014

(C) The Author(s) 2014. This article is published with open access at Springerlink.com

\begin{abstract}
Dialysis is a life-sustaining treatment for patients with end-stage kidney disease. In a different context, for many patients this treatment is the focal point around which their life revolves, not only due to the time spent travelling to and from treatment sessions and the time dedicated to the dialysis treatment itself, but also due to the accompanying dietary and fluid restrictions and medication burden. Wearable and portable dialysis devices could potentially improve patient quality of life by allowing patients to continue with their daily activities of life while undergoing dialysis, as well as by loosening — or removing entirely — dietary and fluid restrictions and reducing pill burden. Advances in nanotechnology manufacturing coupled with advances in electronics and miniaturisation have allowed a new generation of wearable and portable dialysis devices to be developed which are now undergoing large animal and patient clinical trials. We are therefore potentially at a new dawn in the treatment of dialysis patients with the first generation of wearable and portable dialysis devices, which may well revolutionise the treatment and quality of life for patients with end-stage kidney disease.
\end{abstract}

Keywords Wearable $\cdot$ Portable $\cdot$ Haemodialysis .

Haemofiltration $\cdot$ Peritoneal dialysis

\section{Introduction}

Haemodialysis (HD) was first used by Wilhem Kolff to treat patients with acute kidney injury during the Second World

A. Davenport $(\bowtie)$

UCL Centre for Nephrology, Royal Free Hospital, University

College London Medical School, Rowland Hill Street, London NW3

2PF, UK

e-mail: andrewdavenport@nhs.net
War [1]. However it was only in the 1960s following advances in vascular access, dialysers [2] and dialysis machine design [3] that HD started to become available as a treatment for patients with advanced chronic kidney disease (CKD). The many limitations on patient life style at that time, particularly the strict dietary and fluid restrictions required, were readily appreciated by the early pioneers of HD therapies, who started a search to develop portable and wearable HD devices [4-6]. However the technology available at that time restricted development and, consequently, enthusiasm for developing a wearable device waned.

Why develop a wearable or implantable dialysis device ?

Home HD offers many advantages over centre-based dialysis, and the newer dialysis machine designs reduce the time spent in preparing and cleaning the dialysis machine. However unless patients dialyse overnight, they still potentially lose productive time while attached to the dialysis machine. Thus, a wearable or implantable device could potentially provide patients with the freedom to work and perform their activities of daily living while dialysing, and allow greater dietary choices $[7,8]$.

It could be argued that a portable and wearable dialysis device - in the form of peritoneal dialysis (PD) — has already been developed. However, patients either have to perform three to four exchanges per day with continuous ambulatory PD or connect themselves to an automated overnight cycler which although transportable requires a mains electrical supply and fresh dialysate. A PD system that recycles dialysate would potentially be more eco-friendly, and fewer connections and disconnections could potentially reduce the risk of peritonitis, the commonest cause of PD technique failure $[9,10]$. 
HD is an efficient treatment for removing small watersoluble solutes, but trials have consistently shown that simply increasing urea clearance does not lead to improved patient survival for patients with both acute and chronic kidney failure [11-13]. While adding convective losses to the diffusive clearance of conventional HD can increase the clearance of phosphate and other middle molecular-weight solutes [14, 15], as these are predominantly intracellular, their extracorporeal clearance is more dependent on time than modality (Fig. 1) [16].

More recently, high volume post-dilutional on-line haemodiafiltration treatments have been compared to standard HD[17-20]. The results appear to indicate benefit in terms of patient outcomes [17]: taken individually these trials have a number of potential confounders [18-20], but taken together, higher volume haemodiafiltration does appear to offer improved patient survival [17]. Other trials on HD, involving either frequent HD sessions daily but each of shorter duration or longer nocturnal HD sessions, have not shown the expected improvements from a greater amount of dialysis treatment $[21,22]$. Indeed, a increase number of HD sessions led to a quicker loss of residual renal function, so perhaps negating the benefits of additional dialysis [21, 22]. However, the combination of more frequent dialysis sessions and haemodiafiltration $[5 \times$ week predilution convective flow of $18-271 / \mathrm{m}^{2}$ body surface area (BSA)] in children demonstrated not only excellent biochemical results but also highly significant catch-up growth that was much better than that observed following transplantation [23]. Although this treatment option is an advance, the question arises as to whether dialysis centres have the logistics to provide more frequent haemodialfiltration treatments and equally whether children and their parents are prepared to commit so much time to the treatment. A wearable dialysis device could potentially be a solution to this paradox by combining longer treatment times while allowing patients greater freedom [24].

\section{The new generation of wearable dialysis devices}

\section{PD devices}

The current generation of wearable dialysis devices had to overcome to two important basic design problems: firstly, to operate using powerful small light-weight battery-powered pumps and, secondly, to avoid reliance on fresh dialysate by developing sorbent technology to re-use spent dialysate [25]. The developers of the Vicenza wearable artificial kidney (ViWAK) proposed using a standard fresh glucose-based dialysate that was to be instilled each morning, allowed to dwell for $2 \mathrm{~h}$ and then continuously recycled through a dual lumen PD catheter. The dialysate effluent would be pumped first through a filter to remove proteins and then through a series of sorbent filters, followed by a degassing chamber before returning to the patient [26]. In the evening the patient would drain out the dialysate and instil a fresh bag of $7.5 \%$ icodextrin to aid solute clearance and volume control. Such a system as described would require the patient to perform two standard PD exchanges per day. Due to this limitation and the costs of replacing the sorbents each day, the ViWAK has not proceeded from laboratory to clinical trials.

David Lee and Marty Roberts worked for many years on developing a wearable continuous peritoneal dialysis device [27]. Their current version, the automated wearable artificial kidney (AWAK) is based on regenerating spent PD effluent [28]. As the AWAK uses a standard single lumen PD catheter, then peritoneal dialysate either flows into or out from the patient (Fig. 2a, b), and as such there has to be a chamber to store peritoneal dialysate. The AWAK device comprises two modules, one designed to be changed on a daily basis and the other to be changed monthly [29].

Sorbents can be subclassified into those which either adsorb or absorb molecules. Adsorption is when molecules adhere to the surface of the adsorbent, whereas absorption is when molecules permeate the sorbent and are subsequently
Fig. 1 Patients with chronic kidney disease fail to adequately excrete the products of cellular metabolism. The volume of the intracellular compartment exceeds that of the plasma volume, and the clearance of most middle-sized and charged solutes by the dialyser is time dependent, so favouring more effective clearance with a continuous dialysis system

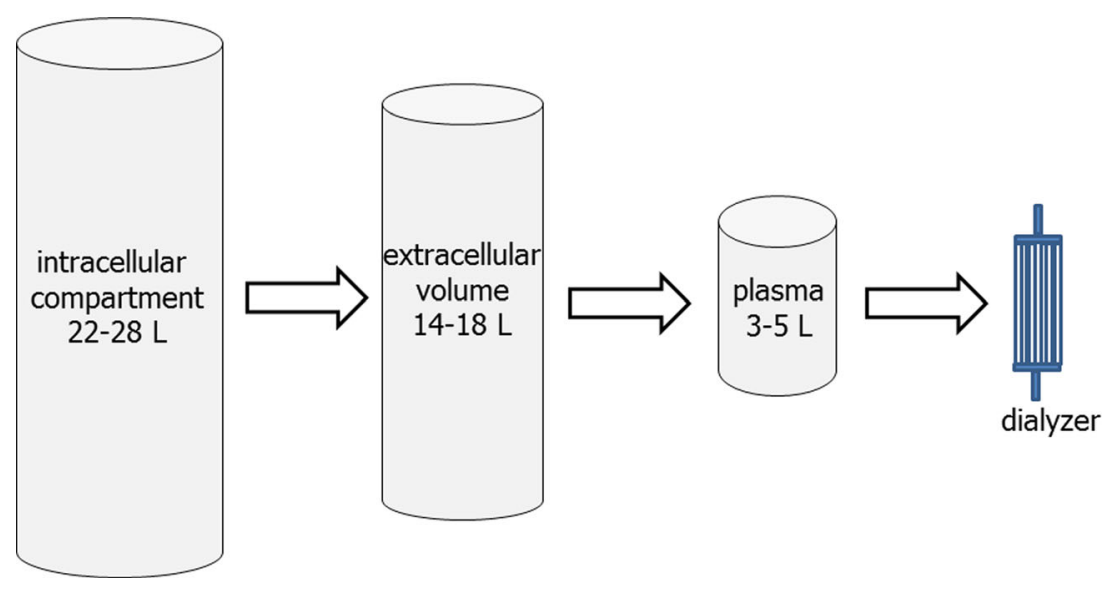


a

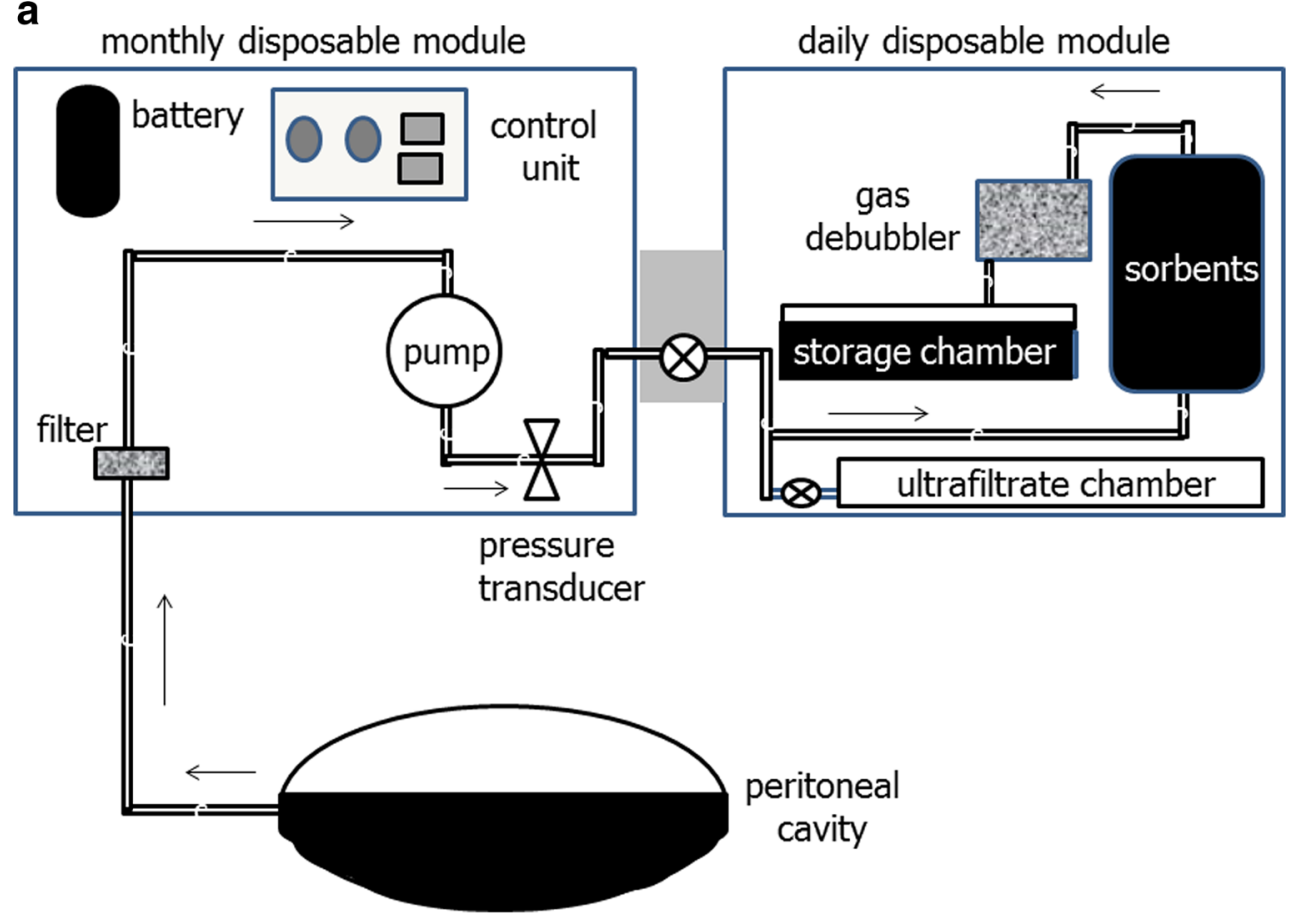

b

monthly disposable module daily disposable module

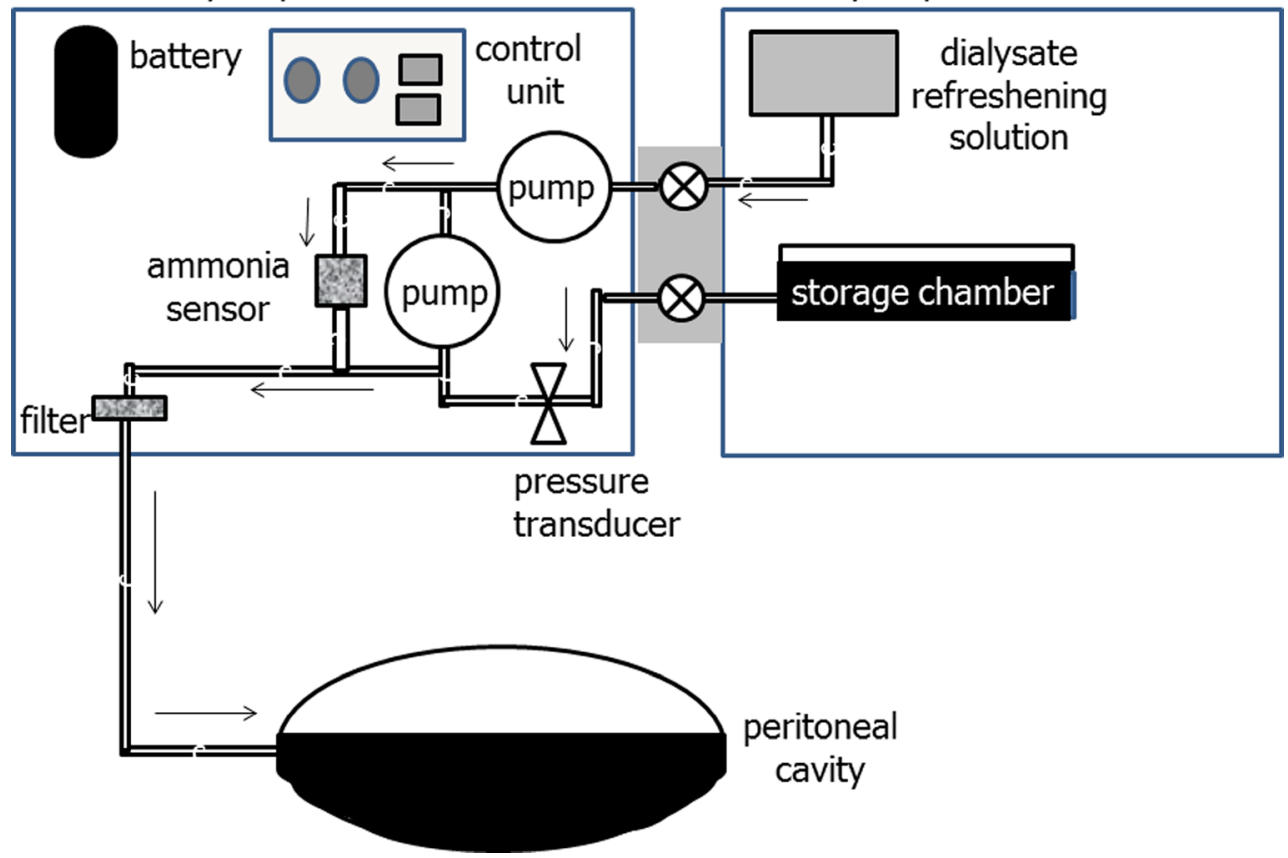

Fig. 2 The automated wearable artificial kidney (AWAK) has a discontinuous flow of peritoneal dialysate. a Outflow circuit with spent dialysate effluents pumped through a fibrin filter and sorbents and then through a degassing chamber before being retained in a storage chamber. There is a

taken up by it. In addition, whereas some sorbents take up molecules until they become saturated, others act primarily by exchanging one molecule for another [30]. For example, many separate collecting chamber for ultrafiltrate. b The AWAK in-flow circuit with spent dialysate refreshed by the addition of glucose, bicarbonate and electrolytes before being passed through an ammonia sensor and then pumped back into the patient

sorbents use activated microporous carbons which both adsorb and absorb many compounds, including heavy metals, oxidants, chloramines, creatinine, other organic species, 
middle molecules, including beta 2 microglobulin, and also the protein-bound solutes indoxyl-sulphate and $p$ aminohippurate [31]. Urea is cleared enzymatically in the AWAK using urease, which converts urea into ammonium carbonate, producing ammonia and carbon dioxide. As ammonia is toxic, the sorbent system has to contain compounds designed to remove ammonia [32]. Zirconium phosphate will readily adsorb ammonium, but also potassium, calcium, magnesium and other cations and metals. However, when zirconium phosphate adsorbs these molecules they are exchanged, thereby releasing hydrogen and to a lesser extent sodium ions. As hydrogen ion release is not desirable, yet another sorbent is required to remove these hydrogen ions. Zirconium carbonate will absorb hydrogen ions, along with phosphate, fluoride and heavy metals, but once again adsorption is by exchange, so releasing bicarbonate, acetate and to a lesser extent sodium [33].

Although azotaemic toxins are removed by the sorbents, there will also be some changes in electrolytes. Glucose and lactate will have been lost through diffusion from the peritoneal cavity so the dialysate will need to be refreshed by adding glucose, bicarbonate and electrolytes [34] (Fig. 2b). The refreshed dialysate is then pumped back into the patient after passing through an ammonia sensor. This sensor has been designed as a safety mechanism to detect the very small quantities of ammonia which start to enter the dialysate when the sorbents have neared their capacity to adsorb ammonium, thus warning the patient that fresh sorbents are required. Compared to the conventional PD modality, the AWAK design proposes a tidal protocol with a residual volume of 500 $1,000 \mathrm{ml}$ with rapid exchanges of around $250-\mathrm{ml}$ aliquots aiming for exchanges of around $4 \mathrm{l} / \mathrm{h}$ [35]. Although the pumps are operated by small light-weight rechargeable batteries, they require recharging overnight.

One of the key decisions to be made in designing a portable or wearable device is to determine the amount of sorbent to be used, as too little sorbent will lead to earlier saturation and sorbent exhaustion with increased frequency of sorbent exchanges, whereas although additional sorbent will reduce the frequency of sorbent exchanges, it will add extra weight [36]. Thus, designers have to take care to balance what weight patients are prepared to carry around versus the inconvenience of sorbent exchange. Taking these considerations into account, the AWAK design has two proposed versions, one weighing around $1 \mathrm{~kg}$ and the other $3 \mathrm{~kg}$, depending on the difference in the size of the sorbent cartridges. Replacing the sorbents currently requires the patient to drain out peritoneal dialysate and then re-instil fresh dialysate with each sorbent exchange. Thus, it is important that the sorbents last for at least $24 \mathrm{~h}$ to prevent the patient having to perform additional PD exchanges.

Clinical trials aimed at testing the capacity of the current sorbents are expected in 2015. Not surprisingly, the recent enthusiasm for developing wearable and portable dialysis devices has sparked new interest and research into a new generation of more effective and lighter weight sorbents [37].

Wearable ultrafiltration and haemofiltration devices

The advent of dialysers with increased hydraulic permeability [2] led to the development of wearable and portable haemofiltration designs. However, for haemofiltration to provide effective clearance, large ultrafiltration volumes with the corresponding return of large volumes of a replacement fluid are required. These technical difficulties led to the abandonment of the first generation of wearable haemofiltration devices [38] or resulted in devices being limited to providing low volume ultrafiltration for the treatment of refractory heart failure rather than for treatment of end-stage kidney disease [39]. More recently, a new design based on passing a plasma ultrafiltrate through a silica-based nanoclay sorbent has been developed (Fig. 3) [40], with the majority of plasma ultrafiltrate being returned (to the patient), but some expelled to control fluid balance. As yet, clinical trials of this prototype have been limited to large animal studies with goats. More work is required to refine this design and to determine the capacity of the silica-based nanoclay sorbents.

\section{Wearable HD devices}

The advent of nanotechnology manufacturing techniques coupled with miniaturisation and computer technology has
Fig. 3 A prototype wearable haemofiltration device using a plasma haemofilter silica-based nanoclay sorbent

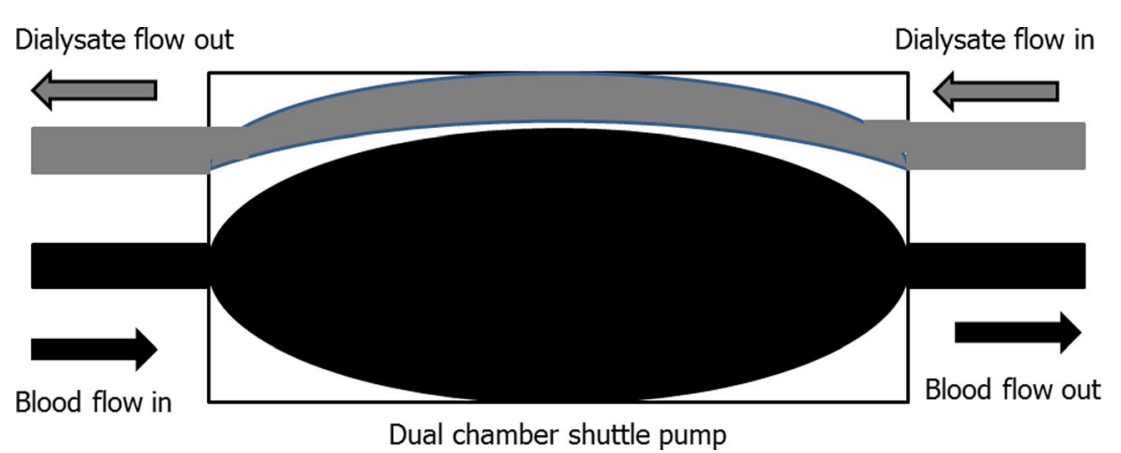

Dual chamber shuttle pump 
allowed the development of experimental wearable HD devices [41]. Current designs are based on the concept of pumping blood and dialysate in a counter-current direction through a standard high-flux dialyser [42]. A single dual chamber battery powered shuttle pump was designed in order to reduce weight and power requirements (Fig. 4). The standard HD machine blood pump produces an almost constant blood flow into the dialyser at a relatively constant pressure. In contrast, the dual chamber shuttle pump pumps blood and dialysate at almost equal flow rates of around $50 \mathrm{ml} / \mathrm{min}$, but as this pump either pumps blood or dialysate, it produces oscillating pressure gradients across the dialyser membrane [43]. The standard HD session is based on delivering a highly efficient but short duration treatment, so although protein deposition on the dialyser membrane and membrane fouling reduce treatment efficiency somewhat, this is not clinically relevant in routine practice. However, for the lower efficiency wearable device which produces much lower creatinine and urea clearances, i.e. of approximately $20-30 \mathrm{ml} / \mathrm{min}$ [44], then membrane fouling could potentially markedly reduce efficiency over time. As such, one of the key designs behind the WAK is the shuttle pump, which by generating a pulsatile flow across the dialyser membrane, minimises dialyser membrane protein deposition, thereby maintaining solute clearances over time [45]. A low-sodium sterile dialysate is pumped through the dialyser and then through a series of sorbents in the order of activated microporous carbon, followed by urease to remove urea and then by a number of zirconium-containing sorbents to remove ammonium and hydrogen ions. As these latter sorbents are in effect ion exchangers, they will then release bicarbonate and sodium. Before returning through the dialyser, the dialysate needs to be refreshed by adding bicarbonate, sodium, calcium and magnesium (Fig. 5) [44]. Currently the WAK has only been worn by patients for up to $8 \mathrm{~h}$. Consequently, new trials of treating patients for $24 \mathrm{~h}$ are planned later this year to determine the capacity of the sorbents and the composition and requirements of the electrolyte refreshing solution, as these are likely to vary between patients.

As with the AWAK, microbubbles of carbon dioxide develop within the extracorporeal circuit, both in the dialysate and blood compartments. Whereas the conventional HD circuit has an arterial expansion chamber and venous bubble chamber which can accommodate microbubbles, the WAK has no such chambers and, therefore, parts of the plastic tubing in the circuit have been designed using water-impermeable but gas-permeable plastics [43].

The main disadvantage of a wearable HD device is that there is a risk of clotting in the extracorporeal circuit. In the intensive care setting many continuous forms of renal replacement therapy have to be replaced due to circuit clotting [46]. Although there are differences in the balance of pro- and anticoagulants between critically ill patients with acute kidney injury and those with end stage kidney disease [47, 48], clotting in the extracorporeal circuit remains a major hurdle to overcome. It is important to design the blood circuit to minimise areas of turbulence and stagnation, as well as blood-air interfaces as these promote clotting. Equally important is dialyser design and priming to minimise air and microbubble entrapment during priming and operating. Appropriate selection of the central venous access catheter and dialyser design [49], coupled with the dual chamber pump, can all help towards reducing the risk of clotting in the extracorporeal circuit. Currently, a bolus followed by a continuous infusion of unfractionated heparin has been used to anticoagulate patients using the WAK. Repeated exposure to unfractionated heparin has been reported to lead to osteoporosis; in addition, patients differ in heparin requirements. Other alternatives, including repeated daily bolus injections of low-molecular-weight heparins or of heparinoids which have a much longer half-life, have not been explored. The ideal extracorporeal anticoagulant would be an oral
Fig. 4 The wearable artificial kidney (WAK) utilises a dual chamber shuttle pump which either pumps blood or dialysate in a counter-current direction

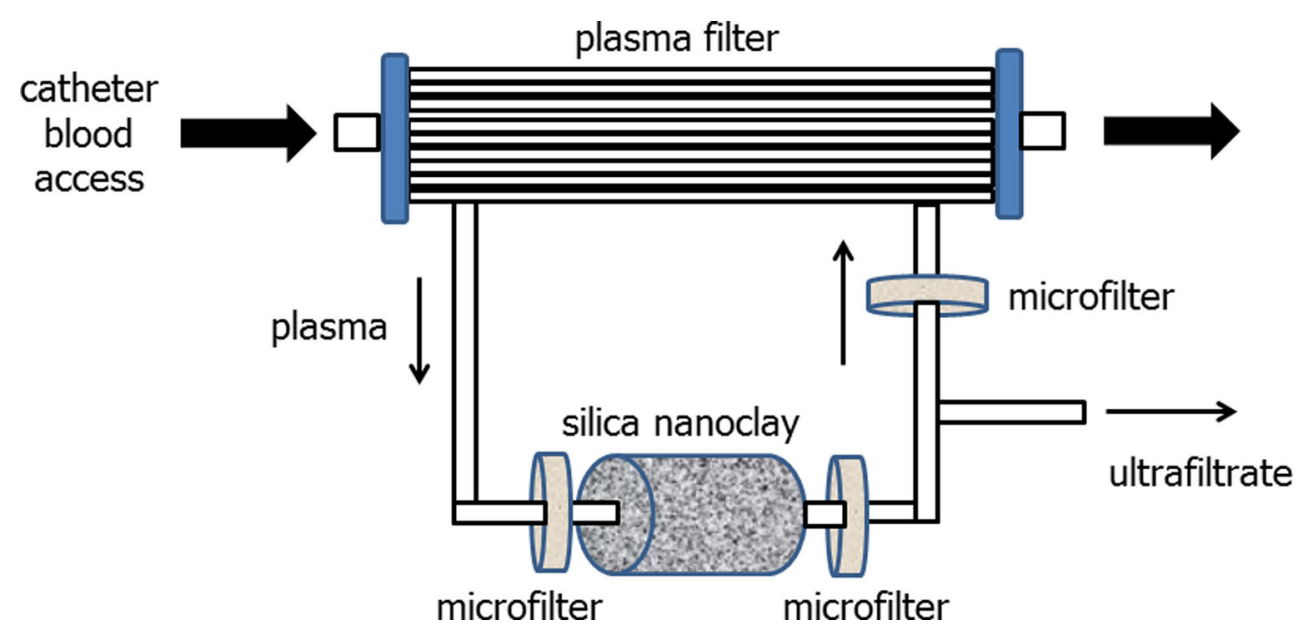


Fig. 5 The WAK has both a blood side and a dialysate side, with spent dialysate regenerated by passage through a series of sorbents, followed by the addition of bicarbonate and electrolytes

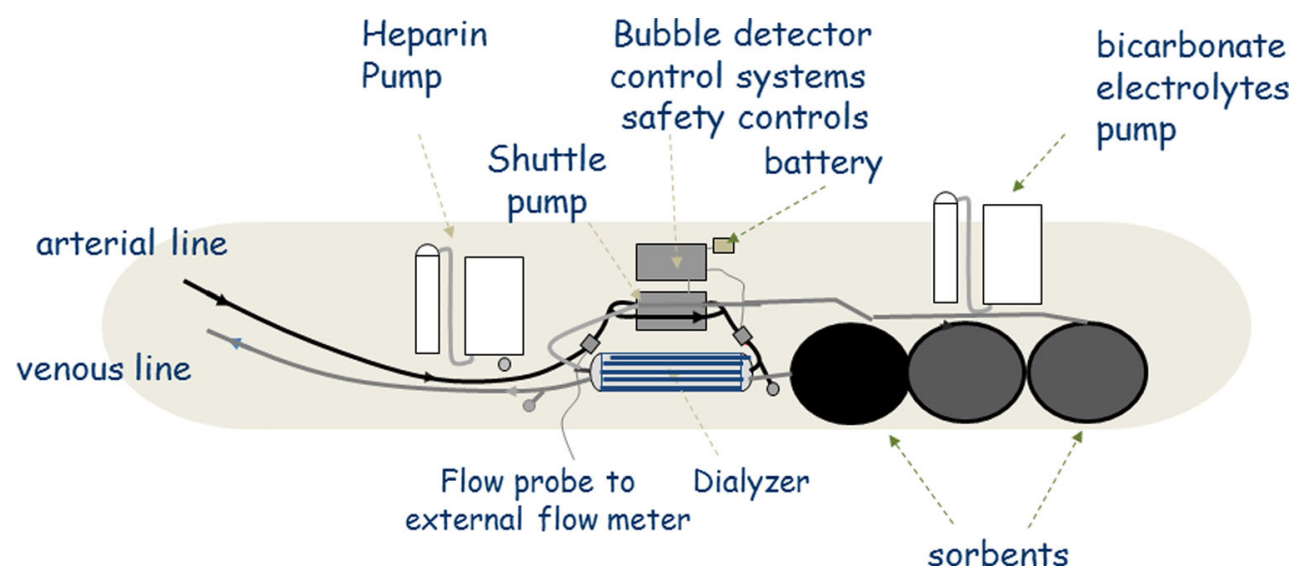

medication that had predictable effects and so would not require regular monitoring and, preferably, not be a systemic anticoagulant. Currently only oral systemic anticoagulants are available. Consequently, such future designs of wearable HD devices may require alternative anticoagulant strategies $[50,51]$, such as oral anti-thrombin or anti-factor Xa inhibitors.

\section{Implantable HD devices}

The commercial market for wearable and portable dialysis devices would be limited to the more active and self-reliant patient, whereas an implantable device could potentially be made available to all dialysis patients. However, any implantable device not only has to have minimal risks for insertion but also has to operate effectively and not fail prematurely. Currently there are no implantable devices undergoing trials, but research is underway to overcome the three main hurdles faced by an implantable dialysis device. Implanting a device between the iliac arteries and veins has the advantage of not requiring a blood pump. Although arterial grafts have been a major success in treating patients with arterial vascular disease, arterio-venous grafts have not been as successful for HD access due to an increased risk of graft thrombosis. As such, thrombus of access darts has been a major hurdle to overcome [52], although polyethylene glycol coating of silicone vascular access darts can reduce or even prevent thrombus formation in the short term $[52,53]$. These access darts provide a high blood flow which would lead to an increased risk of protein deposition and clotting if used with conventional haemodialyser designs. Different dialyser designs based on the glomerular basement membrane, which produces a large volume ultrafiltrate from a high-pressure arteriolar input, have been developed using ultrathin silicone slit membranes, similar to a storm drain in the street [54]. In the healthy kidney, although a large volume of ultrafiltrate is produced by the glomerulus, there is then a highly specialised renal tubule designed to selectively reabsorb most of the glomerular filtrate. So although design technology could come up with an equivalent artificial glomerulus design, the search is still on for an equivalent of the human renal tubule. The reverse osmosis water purification system uses a tightly coiled membrane to separate domestic tap water into waste water and a much smaller amount of water for dialysis. This principle could be used to treat the large volume of filtrate, i.e. to reduce the volume, but it would not provide the highly selective capacity provided by the renal tubule in terms of which solutes to conserve and which to discard. A more futuristic approach would be to try and develop an artificial cell-based renal tubule, but even so the function and cell types in the human renal tubule differ from segment to segment of the tubule [55].

\section{Summary}

The concept of wearable and portable dialysis devices dates back to the pioneering days of the 1970s. However, it is only recently with the more recent advances in nanotechnology manufacturing processes, miniaturisation and computer technology has it been possible to develop a number of wearable and portable devices based on PD, haemofiltration and HD. The current generation of wearable devices weigh between 1$3 \mathrm{~kg}$, as there is a balance between sorbent life and sorbent exchanges. As such the weight of the devices may well restrict their use. However, this renewed interest in wearable devices has equally led to improvements in sorbent technology that hopefully will lead to lighter weight devices and underpins the potential success of these devices. We therefore look forward to the development of a newer generation of dialysis devices which could potentially substantially improve the quality of life of the patient with CKD.

Open Access This article is distributed under the terms of the Creative Commons Attribution License which permits any use, distribution, and 
reproduction in any medium, provided the original author(s) and the source are credited.

\section{References}

1. Kelemen WA, Kolff WJ (1958) An evaluation of the management of acute renal failure with dialysis. AMA Arch Intern Med 102(6):871880

2. Davenport A (2010) Membrane designs and composition for hemodialysis, hemofiltration and hemodialfiltration: past, present and future. Minerva Urol Nefrol 62(1):29-40

3. Davenport A (2009) Can advances in hemodialysis machine technology prevent intradialytic hypotension? Semin Dial 22(3):231-236

4. Jacobsen SC, Stephen RL, Bulloch EC, Luntz RD, Kolf WJ (1975) A wearable artificial kidney: functional description of hardware and clinical results. Proc Clin Dial Transplant Forum 5:65-71

5. Stephens RL, Jacobsen SC, Atkin-Thor E, Kolf WJ (1976) A portable wearable artificial kidney (WAK) initial evaluation. Proc Eur Dial Transplant Assoc 2:511-518

6. Lande AJ, Roberts M, Pecker EA (1977) In search of a 24 hours per day artificial kidney. J Dial 1(8):805-823

7. Ronco C, Davenport A, Gura V (2008) A wearable artificial kidney: dream or reality? Nat Clin Pract Nephrol 4(11):604-605

8. Caplin B, Kumar S, Davenport A (2011) Patients' perspective of haemodialysis-associated symptoms. Nephrol Dial Transplant 26: 2656-2663

9. Davenport A, Wellsted D, Pan Thames Renal Audit Peritoneal Dialysis Group (2011) Does antifungal prophylaxis with daily oral fluconazole reduce the risk of fungal peritonitis in peritoneal dialysis patients? The Pan Thames Renal Audit. Blood Purif 32(3):181-185

10. Davenport A (2009) Peritonitis remains the major clinical complication of peritoneal dialysis: the London, UK, Peritonitis Audit 20022003. Perit Dial Int 29(3):297-302

11. VA/NIH Acute Renal Failure Trial Network, Palevsky PM, Zhang JH, O'Connor TZ, Chertow GM, Crowley ST, Choudhury D, Finkel K, Kellum JA, Paganini E, Schein RM, Smith MW, Swanson KM, Thompson BT, Vijayan A, Watnick S, Star RA, Peduzzi P (2008) Intensity of renal support in critically ill patients with acute kidney injury. N Engl J Med 359(1):7-20

12. Eknoyan G, Beck GJ, Cheung AK, Daugirdas JT, Greene T, Kusek JW, Allon M, Bailey J, Delmez JA, Depner TA, Dwyer JT, Levey AS, Levin NW, Milford E, Ornt DB, Rocco MV, Schulman G, Schwab SJ, Teehan BP, Toto R, Hemodialysis (HEMO) Study Group (2002) Effect of dialysis dose and membrane flux in maintenance hemodialysis. N Engl J Med 347(25):2010-2019

13. Davenport A, Farrington K (2010) Dialysis dose in acute kidney injury and chronic dialysis. Lancet 375(9716):705-706

14. Davenport A, Gardner C, Delaney M, Pan Thames Renal Audit Group (2010) The effect of dialysis modality on phosphate control : haemodialysis compared to haemodiafiltration. The Pan Thames Renal Audit. Nephrol Dial Transplant 25(3):897-901

15. Oates T, Pinney JH, Davenport A (2011) Haemodiafiltration versus high-flux haemodialysis: Effects on phosphate control and erythropoietin response. Am J Nephrol 33(1):70-75

16. Davenport A, Gardner C, Delaney M, Pan Thames Renal Audit Group (2010) Do differences in dialysis prescription impact on KDOQI bone mineral targets? The Pan Thames Renal Audit. Blood Purif 30(2):111-117

17. Mostovaya IM, Blankestijn PJ, Bots ML, Covic A, Davenport A, Grooteman MP, Hegbrant J, Locatelli F, Vanholder R, Nubé MJ, EUDIAL1 - an official ERA-EDTA Working Group (2014) Clinical evidence on hemodiafiltration: a systematic review and a meta-analysis. Semin Dial 27(2):119-127
18. Grooteman MP, van den Dorpel MA, Bots ML, Penne EL, van der Weerd NC, Mazairac AH, den Hoedt $\mathrm{CH}$, van der Tweel I, Lévesque R, Nubé MJ, ter Wee PM, Blankestijn PJ, CONTRA ST Investigators (2012) Effect of online hemodiafiltration on allcause mortality and cardiovascular outcomes. J Am Soc Nephrol 23(6):1087-1096

19. Maduell F, Moreso F, Pons M, Ramos R, Mora-Macià J, Carreras J, Soler J, Torres F, Campistol JM, Martinez-Castelao A, ESHOL Study Group (2013) High-efficiency postdilution online hemodiafiltration reduces all-cause mortality in hemodialysis patients. J Am Soc Nephrol 24(3):487-497

20. Farrington K, Davenport A (2013) The ESHOL study: hemodiafiltration improves survival—but how? Kidney Int 83(6): 979-981

21. Chertow GM, Levin NW, Beck GJ, Depner TA, Eggers PW, Gassman JJ, Gorodetskaya I, Greene T, James S, Larive B, Lindsay RM, Mehta RL, Miller B, Ornt DB, Rajagopalan S, Rastogi A, Rocco MV, Schiller B, Sergeyeva O, Schulman G, Ting GO, Unruh ML, Star RA, Kliger AS, FHN Trial Group (2010) In-center hemodialysis six times per week versus three times per week. N Engl J Med 363(24):2287-2300

22. Daugirdas JT, Greene T, Rocco MV, Kaysen GA, Depner TA, Levin NW, Chertow GM, Ornt DB, Raimann JG, Larive B, Kliger AS, FHN Trial Group (2013) Effect of frequent hemodialysis on residual kidney function. Kidney Int 83(5):949-958

23. Fischbach M, Terzic J, Menouer S, Dheu C, Seuge L, Zalosczic A (2010) Daily on line haemodiafiltration promotes catch-up growth in children on chronic dialysis. Nephrol Dial Transplant 25(3):867-873

24. Ronco C, Davenport A, Gura V (2008) Toward the wearable artificial kidney. Hemodial Int 12[Suppl 1]:S40-7

25. Davenport A, Ronco C, Gura V (2010) Portable and wearable dialysis: where are we now? Hemodial Int 14[Suppl 1]:S22-6

26. Ronco C, Fecondini L (2007) The Vicenza wearable artificial kidney for peritoneal dialysis (ViWAK PD). Blood Purif 25:383-388

27. Lee DBN, Roberts M (2008) A peritoneal based automated wearable artificial kidney. Clin Exp Nephrol 12:171-180

28. Ronco C, Davenport A, Gura V (2011) The future of the artificial kidney: moving towards wearable and miniaturized devices. Nefrologia 31(1):9-16

29. Fissell WH, Roy S, Davenport A (2013) Achieving more frequent and longer dialysis for the majority: wearable dialysis and implantable artificial kidney devices. Kidney Int 84(2):256-264

30. Davenport A (2011) Role of dialysis technology in the removal of uremic toxins. Hemodial Int Suppl 1:S49-53

31. Sandeman SR, Howell CA, Phillips GJ, Zheng Y, Standen G, Pletzenauer R, Davenport A, Basnayake K, Boyd O, Holt S, Mikhalovsky SV (2014) An adsorbent monolith device to augment the removal of uraemic toxins during haemodialysis. J Mater Sci Mater Med 25(6):1589-1597

32. Roberts M, Ash SR, Lee DB (1999) Innovative peritoneal dialysis: flow-thru and dialysate regeneration. ASAIO J 45(5):372-378

33. Rosenbaum BP, Ash SR, Wong RJ, Thompson RP, Carr DJ (2008) Prediction of hemodialysis sorbent cartridge urea nitrogen capacity and sodium release from in vitro tests. Hemodial Int 2(2):244-253

34. Davenport A (2012) Portable or wearable peritoneal devices-the next step forward for peritoneal dialysis? Adv Perit Dial 28:97-101

35. Roberts M, Lee DBN (2006) Wearable artificial kidneys. A peritoneal dialysis approach. Dial Transplant 36:780-782

36. Maroni BJ, Steinman TI, Mitch WE (1985) A method for estimating nitrogen intake of patients with chronic renal failure. Kidney Int 27: $58-65$

37. Winchester JF, Ronco C (2010) Sorbent augmented hemodialysis systems: are we there yet? J Am Soc Nephrol 21(2):209-211

38. Murisasco A, Baz M, Boobes Y, Bertocchio P, el Mehdi M, Durand C, Reynier JP, Ragon A (1986) A continuous hemofiltration system, using sorbents for hemofiltrate regeneration. Clin Nephrol 26[Suppl]:S53-S57 
39. Gura V, Ronco C, Nalesso F, Brendolan A, Beizai M, Ezon C, Davenport A, Rambod E (2008) A wearable haemofilter: first human study of slow continuous ambulatory ultrafiltration. Kidney Int 74: 497-502

40. Wester M, Simonis F, Gerritsen KG, Boer WH, Wodzig WK, Kooman JP, Joles JA (2013) A regenerable potassium and phosphate sorbent system to enhance dialysis efficacy and device portability: an in vitro study. Nephrol Dial Transplant 28(9):2364-2371

41. Gura V, Ronco C, Davenport A (2009) The wearable artificial kidney, why and how: from holy grail to reality. Semin Dial 22(1):13-17

42. Davenport A, Will EJ, Davison AM (1990) Effect of the direction of dialysate flow on the efficiency of continuous arteriovenous haemodialysis. Blood Purif 8(6):329-336

43. Davenport A, Ronco C, Gura V (2011) From wearable ultrafiltration device to wearable artificial kidney. Contrib Nephrol 171:237-242

44. Davenport A, Gura V, Ronco C, Beizai M, Ezon C, Rambod E (2007) A wearable hemodialysis device for patients with end-stage renal failure: a pilot study. Lancet 370:2005-2010

45. Gura V, Davenport A, Beizai M, Ezon C, Ronco C (2009) Beta2microglobulin and phosphate clearances using a wearable artificial kidney: a pilot study. Am J Kidney Dis 54(1):104-11

46. Davenport A (2004) Anticoagulation for continuous renal replacement therapy. Contrib Nephrol 44:228-238

47. Agarwal B, Gatt A, Riddell A, Wright G, Chowdary P, Jalan R, Burroughs AK, Davenport A (2013) Hemostasis in patients with acute kidney injury secondary to acute liver failure. Kidney Int 84(1):158-163
48. Agarwal B, Shaw S, Shankar Hari M, Burroughs AK, Davenport A (2009) Continuous renal replacement therapy (CRRT) in patients with liver disease: is circuit life different? J Hepatol 51(3):504-509

49. Vernon K, Peasegood J, Riddell A, Davenport A (2010) Dialyzers designed to increase internal filtration do not result in significantly increased platelet activation and thrombin generation. Nephron Clin Pract 117:c403-c408

50. Lutz J, Menke J, Sollinger D, Schinzel H, Thürmel K (2014) Haemostasis in chronic kidney disease. Nephrol Dial Transplant 29(1):29-40

51. Davenport A (2012) Alternatives to standard unfractionated heparin for pediatric hemodialysis treatments. Pediatr Nephrol 27(10):18691879

52. Melvin ME, Fissell WH, Roy S, Brown DL (2010) Silicon induces minimal thromboinflammatory response during 28-day intravascular implant testing. ASAIO J 56:344-348

53. Muthusubramaniam L, Lowe R, Fissell WH, Li L, Marchant RE, Desai TA, Roy S (2011) Hemocompatibility of silicon-based substrates for biomedical implant applications. Ann Biomed Eng 39(4): $1296-1330$

54. Fissell WH, Dubnisheva A, Eldridge AN, Fleischman AJ, Zydney AL, Roy S (2009) High-performance silicon nanopore hemofiltration membranes. J Membr Sci 326:58-63

55. Humes HD, Fissell WH, Weitzel WF, Buffington DA, Westover AJ, MacKay SM, Gutierrez JM (2002) Metabolic replacement of kidney function in uremic animals with a bioartificial kidney containing human cells. Am J Kidney Dis 39:1078-1087 